\title{
Intraseasonal Variability of Rainfall and Its Effect on Interannual Variability across the Indian Subcontinent and the Tibetan Plateau
}

\author{
XINGWEN JIANG \\ Institute of Plateau Meteorology, China Meteorological Administration, and Heavy Rain and Drought-Flood \\ Disasters in Plateau and Basin Key Laboratory of Sichuan Province, Chengdu, Sichuan, China \\ MingFANG TING \\ Lamont-Doherty Earth Observatory, Columbia University, Palisades, New York
}

(Manuscript received 21 May 2018, in final form 25 January 2019)

\begin{abstract}
Intraseasonal variability of rainfall over the Indian subcontinent (IS) and the Tibetan Plateau (TP) has been discussed widely but often separately. In this study, we investigate the covariability of rainfall across the IS and the TP on intraseasonal time scales and its impact on interannual variability of regional rainfall. The most dominant mode of rainfall intraseasonal variability across the region features a dipole pattern with significant out-of-phase rainfall anomalies between the southeastern TP and the central and northern IS. This dipole rainfall pattern is associated with intraseasonal oscillations (ISOs) of 10-20 days and 30-60 days, especially the latter. An active spell of rainfall in the central and northern IS (southeastern TP) is associated with the strengthening (northward shift) of water vapor transport of the Indian summer monsoon, resulting in more water vapor entering into the central and northern IS (southeastern TP) and thus more rainfall. The 10-20-day ISO of the dipole rainfall pattern is caused by the 10-20-day atmospheric ISO in both the tropics and the extratropics, whereas the 30-60-day ISO of the dipole rainfall pattern is only associated with atmospheric ISO in the tropics. The dipole rainfall pattern resembles the most dominant mode of interannual variability of July-August mean rainfall. The 30-60-day ISO of the dipole rainfall pattern has an important contribution to the dipole pattern of July-August mean rainfall anomalies on an interannual time scale due to the different frequencies of occurrence of the active and break phases.
\end{abstract}

\section{Introduction}

The active-break cycles of Asian summer monsoon are often associated with intraseasonal oscillations (ISOs) with periods of 10-20 and 30-60 days (e.g., Annamalai and Slingo 2001; Goswami 2012; Jia and Yang 2013). The ISOs of monsoon rainfall can affect the seasonalmean rainfall amount (Goswami and Ajayamohan 2001; Goswami and Xavier 2005; Krishnamurthy and Shukla 2007, 2008) and the activity of synoptic systems such as monsoon lows (e.g., Goswami et al. 2003; Hatsuzuka and Fujinami 2017). In addition, the monsoon ISOs also exert an impact on extratropical circulation (e.g., Ding and Wang 2007). Thus, variations of ISOs in Asian monsoon region are important for seasonal and extended-range prediction of rainfall

Corresponding author: Dr. Xingwen Jiang, xingwen.jiang@ yahoo.com over both the tropics and the extratropics (e.g., Ding et al. 2010, 2011).

The Tibetan Plateau (TP) plays a critical role in the evolution of Asian climate and weather (e.g., Wu et al. 2007; Wang et al. 2014). The ISO of most atmospheric variables over the TP exhibits both 10-20- and 30-60-day signals (Fujinami and Yasunari 2004; Wang and Duan 2015). The 10-20-day ISO is statistically significant in most years whereas the 30-60-day ISO is only significant in some years (Wang and Duan 2015). Both the 10-20- and 30-60-day ISOs over the TP have an impact on regional synoptic disturbances (Zhang et al. 2014) and circulation (Liu and Lin 1991).

Fujinami and Yasunari (2004) reported that the 10-20-day ISO rotates clockwise around the TP, affecting the TP, Indochina, the Bay of Bengal, and India. The 10-20-day ISO over the TP is associated with a well-developed wave train extending from North Africa to Asia along the Asian subtropical jet 
(Fujinami and Yasunari 2004; Hu et al. 2016) and a westward propagation of the 10-20-day ISO in the tropics (Yang et al. 2014; Fujinami et al. 2014; Wang and Duan 2015; Murata et al. 2017). Intraseasonal variation of rainfall south of the TP is modulated by the covariability of the 10-20-day ISO between the tropics and midlatitudes (Fujinami et al. 2014). When the 1020-day ISO originating from the South China Sea and the western North Pacific propagates westward to south of the Tibetan Plateau, it can cause oppositesigned convection anomalies between central India and the southeastern TP (e.g., Wang and Duan 2015; Murata et al. (2017).

The 30-60-day ISO over the TP has received less attention compared to the 10-20-day ISO. The most dominant ISO has a period of 30-60 days to the south of the TP, which is linked to the northward propagation of ISO originating from the tropical Indian Ocean (e.g., Hoyos and Webster 2007; Suhas et al. 2013). The northward propagation of the 30-60-day ISO can affect convection anomalies over southern slopes of the TP and possibly lead to out-of-phase convection anomalies between central India and the southern slopes of the TP (Yasunari 1979; Suhas et al. 2013).

The TP, as an elevated heat source in the summer, has been identified as a critical factor for the formation and variability of the Indian summer monsoon (e.g., $\mathrm{Wu}$ et al. 2007). Conversely, some studies also demonstrated that the Indian summer monsoon can affect rainfall over the TP on a wide range of time scales (e.g., Yao et al. 2013; Zhou et al. 2015). Thus, the TP and the Indian summer monsoon should be considered as an interactive system. Indeed, Jiang and Ting (2017) found that interannual variability of the July-August rainfall anomaly across the IS and the TP exhibits a significant dipole pattern. The rainfall anomalies in the TP and the IS are negatively correlated. As both the 10-20- and 30-60-day ISOs can cause out-of-phase convection anomalies between central India and the southern slopes of TP (Suhas et al. 2013; Murata et al. 2017), it is thus interesting to examine whether the dipole rainfall pattern exists on intraseasonal time scales.

The interannual variability of seasonal-mean rainfall is governed by both the slowly varying external component of the forcing (e.g., SST; Hu et al. 2005) and the internal variability component that primarily originates from ISOs (e.g., Goswami 2012). Goswami and Xavier (2005) and Goswami (2012) argued that about $50 \%$ of the total interannual variability of the Asian summer monsoon can be ascribed to the internal component. Jiang and Ting (2017) reported that only a portion of the dipole pattern of July-August mean rainfall anomalies across the IS and the TP on interannual time scale can be explained by SST anomalies in the tropical southeastern Indian Ocean. Thus, it is possible that the dipole rainfall pattern on interannual time scale is partly caused by internal atmospheric variability.

The purpose of this study is to investigate the covariability of rainfall between the TP and the IS on intraseasonal time scales and its link to 10-20- and 30-60-day ISOs, as well as its effect on the out-of-phase rainfall between the TP and the Indian subcontinent (IS) on interannual time scales. In the rest of this paper, the data and methods used are described in section 2. A dipole pattern of intraseasonal variability in rainfall across the IS and the TP and its characteristics are presented in sections 3 and 4 , respectively. The links between the dipole rainfall pattern and the atmospheric ISOs in both the tropics and the extratropics are discussed in section 5. The possible contributions of the dipole rainfall pattern to the dominant mode of interannual variability of July-August mean rainfall anomalies are presented in section 6. Finally, a summary and discussion are provided in section 7 .

\section{Data and methods}

\section{a. Data}

In this study, we use rainfall data from the Asian Precipitation-Highly Resolved Observational Data Integration toward Evaluation of the Water Resources (APHRODITE) to disclose rainfall variations over the IS and the TP. The APHRODITE is a compilation of rain gauge data from weather stations. Because the present study focuses on Asian rainfall, the APHRO_MA_V1101, a subset of APHRODITE covering mostly Asian land area $\left(60^{\circ}-150^{\circ} \mathrm{E}, 15^{\circ} \mathrm{S}-55^{\circ} \mathrm{N}\right)$, is used in this study. This product includes daily rainfall from 1951 to 2007 , with a resolution of $0.5^{\circ}$ in both latitude and longitude. There are large horizontal variations in rainfall between the main body of the TP and the surrounding areas due to the sharp topography gradients. The APHRODITE rainfall has advantages in this region because of its improvement in coverage of rain gauge stations and analysis algorithm (Yatagai et al. 2012).

Additional datasets used in this study include ERAInterim from 1979 to 2014 (Dee et al. 2011), the National Oceanic and Atmospheric Administration interpolated outgoing longwave radiation (OLR) from 1979 to 2007 (Liebmann and Smith 1996), and daily rainfall from the Global Precipitation Climatology Project (GPCP) daily precipitation estimates version 2.2 from 1979 to 2014 (Huffman et al. 2001). 


\section{b. Methods}

Given the multiple time scales considered in this study, it is necessary to first define the relevant means and anomalies used in the study. Let $P_{i, j}(x, y)$; $i=1,2, \ldots, N ; j=1,2, \ldots, M$ be the variable of interest, where $N=365$ days and $M$ is the number of years used in the analysis, and $(x, y)$ represents the horizontal grids. A daily climatology is calculated as

$$
\bar{P}_{i}(x, y)=\frac{1}{M} \sum_{j=1}^{M} P_{i, j}(x, y)
$$

the daily anomalies with respect to the daily climatology are defined as

$$
P_{i, j}^{\prime}(x, y)=P_{i, j}(x, y)-\bar{P}_{i}(x, y),
$$

and the interannual anomalies of the season mean (July-August) are

$$
\bar{P}_{j}^{\prime}(x, y)=\sum_{i=182}^{243} P_{i, j}^{\prime}(x, y), j=1,2, \ldots, M .
$$

To investigate the features of ISOs, the Lanczos filter (Duchon 1979) with 61 weights is applied to daily anomalies in each year to extract the ISO information for the periods of 10-20 and 30-60 days. Empirical orthogonal function (EOF) analysis is used to determine the dominant modes of intraseasonal variability of rainfall across the TP and the IS. Because rainfall over the central IS and the southern slopes of TP is higher than that over rest of the region, the EOF is applied to correlation matrix of precipitation anomalies in this study. To reveal the temporal and spatial structure of the ISOs, lagged regression is applied to June-September (JJAS) daily data of all years. Composite analysis is used to analyze the evolution of convection and circulation associated with different ISOs. A Student's $t$ test is used to determine the statistical significance of the regression and composites. An effective number of independent samples is estimated by the method based on autocorrelation proposed by Davis (1976) (also see Chen 1982).

The fast Fourier transform technique is used to calculate the spectra of rainfall for each year after removing daily rainfall climatology. Mean spectra of rainfall for the 57 (1951-2007) summers (JJAS) is calculated to show the rainfall spectra for all years. A box plot is used to show statistical information of intraseasonal correlation for the 57 summers (JJAS), which shows the maximum, minimum, median, and 25 th and 75th percentiles of the correlation coefficients in this study.

\section{A dominant mode of intraseasonal variability of rainfall across the IS and the TP}

Figure 1a shows the climatological seasonal-mean rainfall and the intraseasonal variance for JJAS over the IS and the TP, calculated from 5-day running-mean daily rainfall anomalies $P_{i, j}^{\prime}(x, y)$. There are two rainfall maxima in the IS, one located along the southwestern coast and the other in central India. The southwest maximum is a result of interaction of the southwesterly monsoon flows with the coastal orography, while the central India maximum is likely related to low pressure systems such as the monsoon low and monsoon depression (Gadgil 2003; Krishnamurthy and Ajayamohan 2010). As for the TP, a rainfall band is located at the southern slopes, with rainfall generally decreasing from the east to the west. Comparison of patterns between mean and the intraseasonal variance of rainfall indicates that the regions with high mean rainfall are collocated with regions of large intraseasonal variability, indicating a tight connection between the two.

An EOF analysis is applied to the temporal correlation matrix of JJAS 5-day running-mean daily rainfall anomalies from 1951 to 2007. The first four EOF modes account for $9.3 \%, 6.9 \%, 5.5 \%$, and $4.8 \%$ of the total variance, respectively. While the four modes are not significantly separated using North's criterion (North et al. 1982), the first mode is distinct and robust across different datasets used. It exhibits a dipole pattern with positive values over the central and eastern TP, northeastern India, and Bangladesh, and negative values over the central and northern IS, as well as the western TP (Fig. 1b).

This dipole pattern can also be seen when the EOF analysis is applied to GPCP rainfall data from 1997 to 2014 (Fig. 1c), which includes rainfall information over oceanic regions. The main difference of the first EOF mode between the two datasets is in the northern TP, where the above-normal rainfall in the APHRODITE data is replaced by below-normal rainfall in the GPCP data. This difference comes mostly from the difference of rainfall between the two datasets rather than the different time periods. Because of the relatively low values of the mean and intraseasonal variance and few surface rain gauge stations in that region, we do not focus on rainfall anomalies in the western and northern TP in this study. Instead, we focus on rainfall anomalies over the central IS and the southeastern TP, outlined by the red boxes in Fig. 1, where both the mean and intraseasonal variance of rainfall are high. 

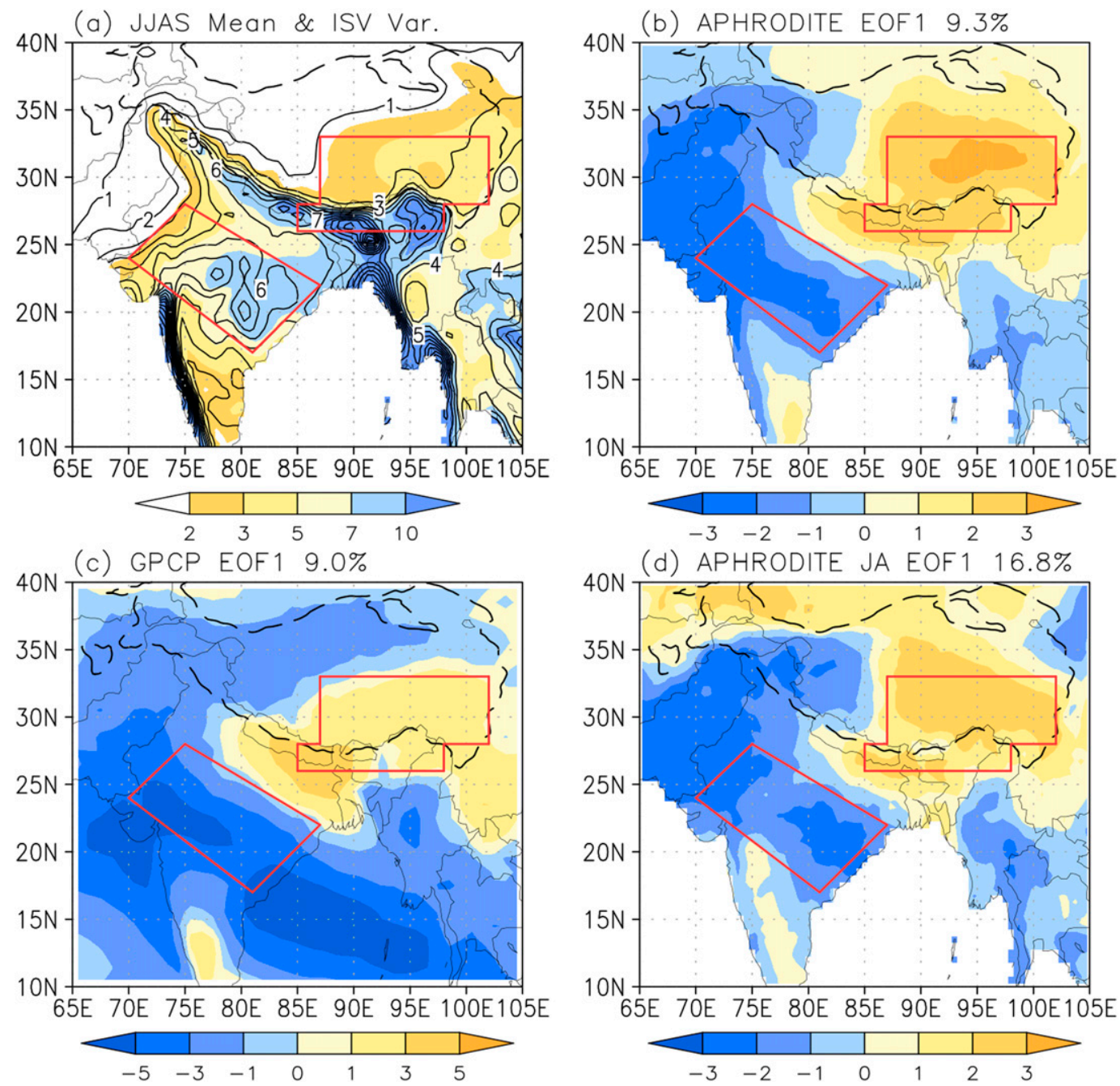

FIG. 1. (a) Mean (mm day ${ }^{-1}$; shading) and intraseasonal variance $\left(\mathrm{mm}^{2} \mathrm{day}^{-2}\right.$; contours) of JJAS APHRODITE rainfall from 1951 to 2007; spatial pattern of the first EOF when applied to temporal correlation matrix of JJAS daily rainfall anomalies from (b) APHRODITE and (c) GPCP (1997-2014) data. (d) Spatial pattern of the first EOF when applied to temporal correlation matrix of July-August mean rainfall anomalies from 1951 to 2007.

Figure 1d shows the first mode of the EOF analysis when applied to temporal correlation matrix of July-August mean rainfall anomalies from 1951 to 2007 , which accounts for $16.8 \%$ of the total variance. It can be seen that the first mode on intraseasonal time scales is almost identical to that on interannual time scales. The possible relationship of the dipole pattern between intraseasonal and interannual time scales will be discussed in section 6 .

To investigate the intraseasonal variability of rainfall in the IS and the TP, we construct two daily rainfall indices. One is the central IS daily rainfall index (CISDR), defined as the regionally averaged daily rainfall anomalies over the central IS; the other is the southeastern TP daily rainfall index (SETPDR), defined as the regionally averaged daily rainfall anomalies over the southeastern TP. The mean power spectra of the 57-yr (1951-2007) JJAS CISDR, SETPDR, and principal component of the first EOF mode (PC1) are shown in Fig. 2. It can be seen that PC1 has statistically significant power spectrum peaks at synoptic (6-9 days) time scales and at quasi 2 weeks and quasi 40 days, and a maximum of variance at a period of quasi 60 days. The PC1 spectra contain significant peaks of both CISDR and SETPDR. However, CISDR (SETPDR) has a more significant time scale at quasi 40 days (quasi 2 weeks), indicating that the dipole pattern may be associated with different physical processes. Because 10-20- and 30-60-day ISOs of monsoon have different features and mechanisms (Annamalai and Slingo 2001), we discuss the dipole 
(a) PC1



(c) CISDR

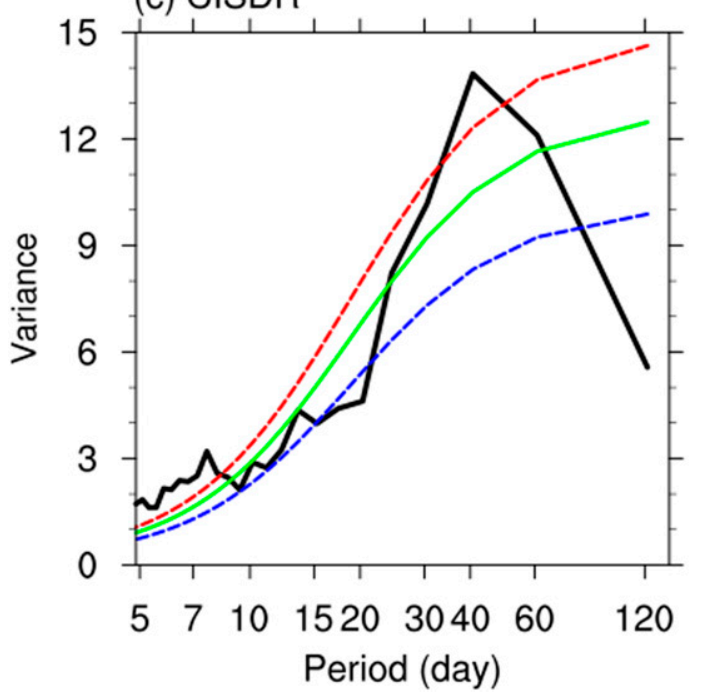

(b) SETPDR

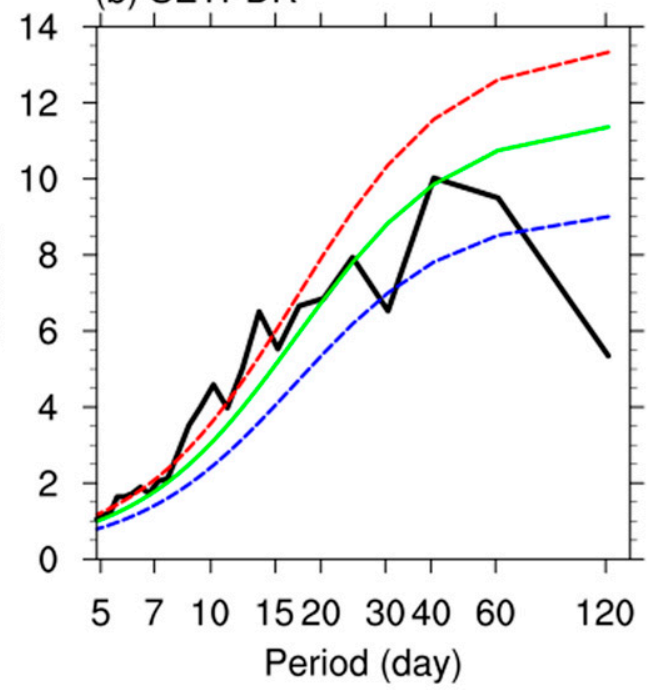

FIG. 2. Mean power spectra (black solid curves) of (a) daily rainfall PC1, and JJAS daily rainfall anomalies averaged in (b) the southeastern Tibetan Plateau and (c) the central Indian subcontinent. Shown are also the Markov red noise spectrum (green solid curves) and its bounds at confidence level of $5 \%$ (blue dashed curves) and $90 \%$ (red dashed curves).

pattern associated with these two intraseasonal time scales here.

After checking the normalized PC1 5-day running means of CISDR and SETPDR, as well as their filtered values for each year, the years 1980 and 1995 are selected to clearly exhibit the out-of-phase variation of rainfall between the central IS and the southeastern TP (Fig. 3). It can be seen that SETPDR generally varies in phase with PC1, but out of phase with CISDR for both the raw and filtered daily rainfall. To further illustrate the out-of-phase relationship of rainfall between the central and northern IS and the SETP, as well as their relationship with $\mathrm{PC} 1$, we calculate correlations among
JJAS PC1, CISDR, and SETPDR for each year (Fig. 4). Although correlations exhibit large interannual spread, PC1 is highly correlated with SETPDR and CISDR for both the unfiltered and filtered values. In general, PC1 correlates more highly with SETPDR than with CISDR. The correlations between SETPDR and CISDR are negative in general (Figs. 4c-f), although the correlations show large fluctuations for different months, filtered values, and years. Based on the median value of the correlations, the correlations in July and August are higher than those in June and September for both raw and the 30-60-day-filtered values. These correlations indicate that rainfall over the central and northern IS 

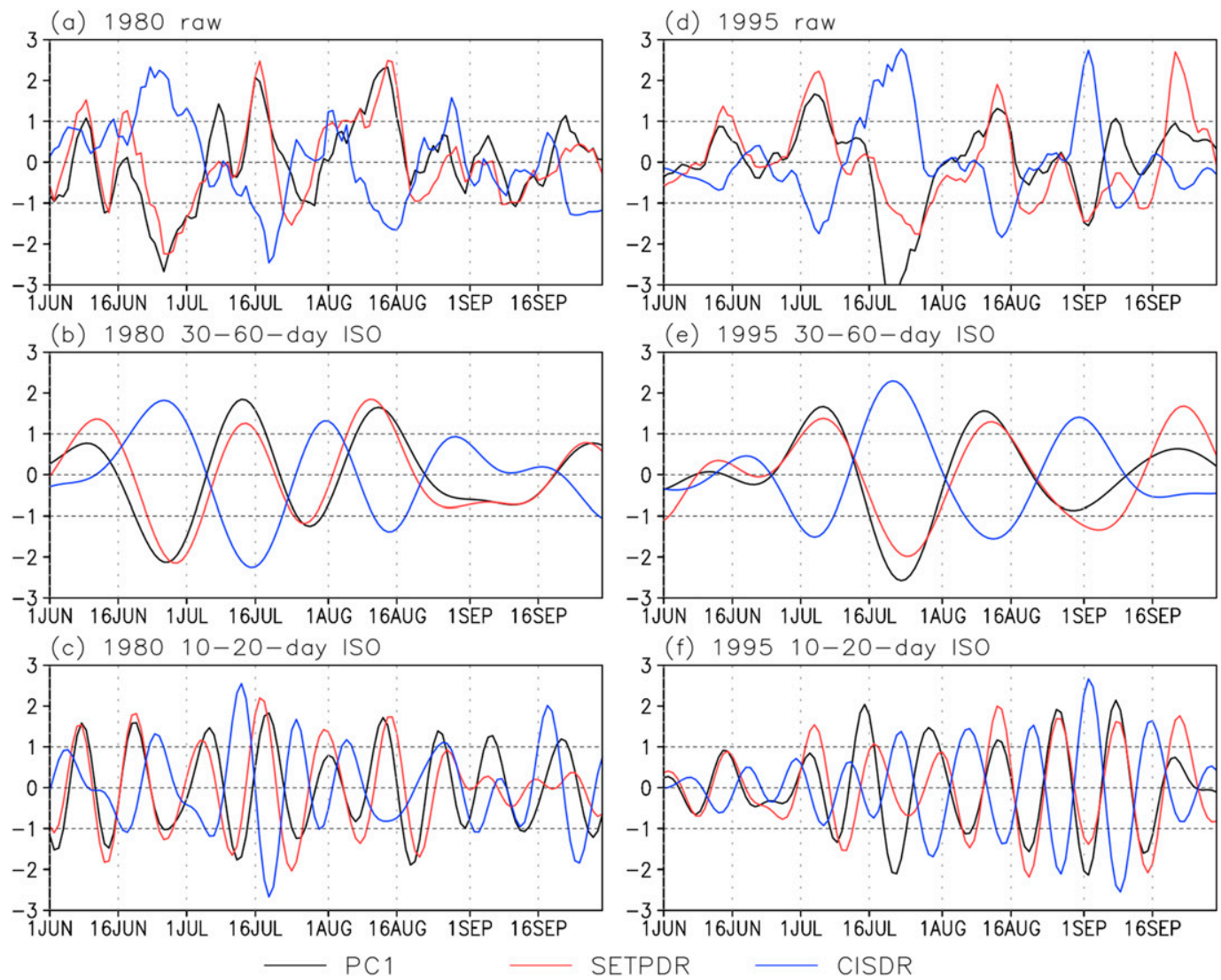

FIG. 3. (a),(d) Normalized time series of daily rainfall PC1 and the 5-day running mean of daily rainfall anomalies over southeastern Tibetan Plateau (SETDPR) and central Indian subcontinent (CISDR), as well as their (c),(f) 1020- and (b),(e) 30-60-day-filtered values for two selected years, (left) 1980 and (right) 1995.

varies out of phase with that over the southeastern TP on intraseasonal time scales, especially for July and August, and the 30-60-day-filtered values. PC1 can well reflect the ISOs of rainfall over the central and northern IS and the southeastern TP. Furthermore, the coefficients of correlation between SETPDR and CISDR are positively correlated with the intraseasonal variance of PC1, with correlation coefficients of 0.41 and 0.33 for the 30-60- and 10-20-day-filtered values, respectively. This suggests that the out-of-phase relationship between SETPDR and CISDR is stronger for the years with stronger ISO.

\section{Active and break spells of rainfall across the IS and the TP}

One of the unique features of the monsoon ISO is the active/break cycle. To further highlight the out-ofphase relationship between rainfall over IS and TP, we investigate its active and break characteristics. We define active (break) phase as when values of normalized PC1 or regionally averaged daily rainfall anomalies are higher (lower) than $+1(-1)$ standard deviation for at least 3 consecutive days for the unfiltered and filtered daily rainfall time series. Figure 5 illustrates the composite differences in rainfall and vertically integrated water vapor transport (WVT) between active and break phases based on PC1, SETPDR, and CISDR. All three difference patterns (Figs. 5a-c) are remarkably similar; all clearly show that an active phase in the central IS (Fig. 5c) is associated with a break phase of rainfall in the southeastern TP, and vice versa. Significant rainfall anomalies are not confined to the IS and the TP. The dipole rainfall pattern is accompanied by significant rainfall anomalies over most parts of Asian land regions. Above-normal rainfall over the central and northern IS is accompanied by above-normal rainfall over most part of the Indo-China Peninsula, but below-normal rainfall in the southeastern $\mathrm{TP}$ and southern China (Fig. 5c).

For Asian land regions, water vapor transported from nearby oceans is important for the formation and variability of local rainfall. An active phase of rainfall 
(a) SETPDR-PC1

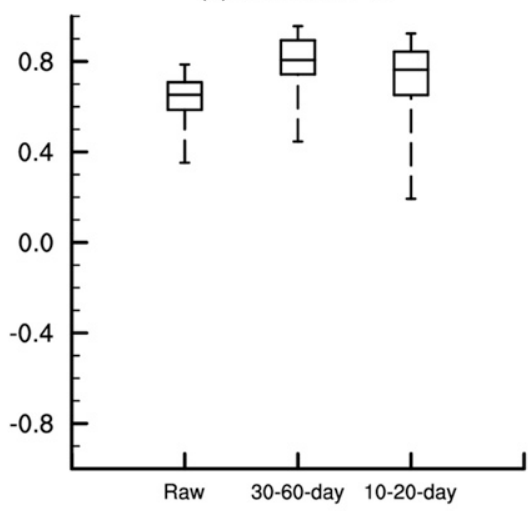

(d) July

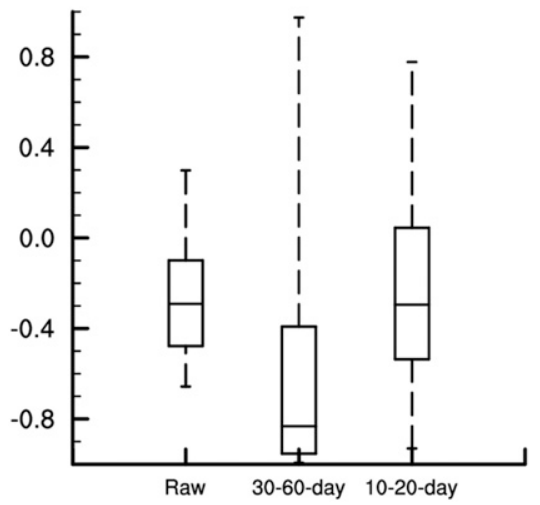

(b) CISDR-PC1

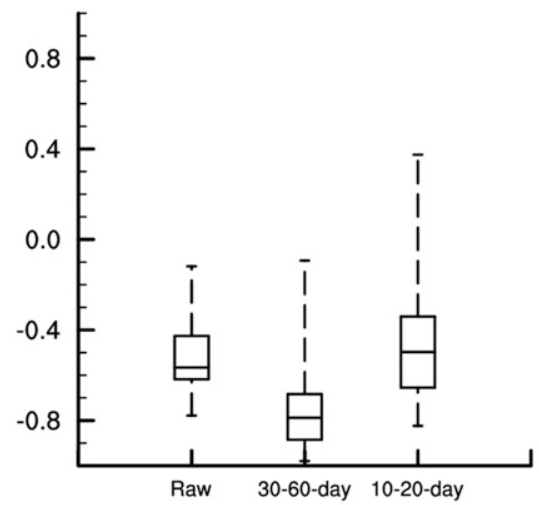

(e) August

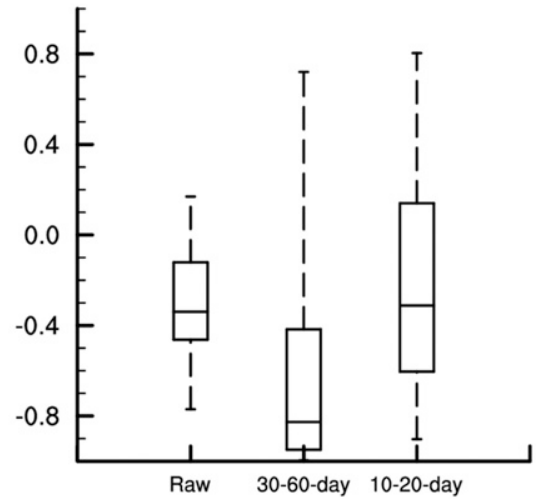

(c) June

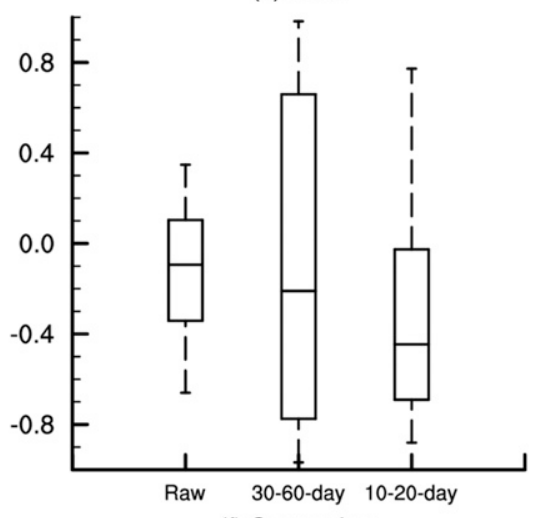

(f) September

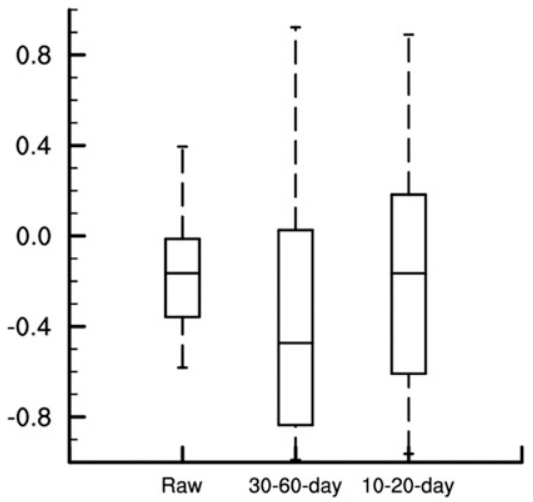

FIG. 4. Box-and-whisker plot of correlation coefficients between PC1 and JJAS daily rainfall anomalies averaged over (a) the southeastern Tibetan Plateau and (b) the central Indian subcontinent for each year from 1951 to 2007. Also shown are box plots of correlation coefficients between SETDPR and CISDR for (c) June, (d) July, (e) August, and (f) September for each year from 1951 to 2007 . Correlations are calculated for raw and 10-20- and 30-60-day-filtered values. The whiskers represent the minimum and maximum of the correlation coefficients for all 57 years.

over the southeastern TP (Fig. 5b) is accompanied by a large-scale anomalous anticyclonic WVT from the IS to the South China Sea, with strong westerly WVT to the south of the TP. On the other hand, an active phase of the Indian summer monsoon (Fig. 5c) is accompanied by anomalous cyclonic WVT over the IS, with easterly WVT to the south of the TP. Comparisons of the anomalous WVT to climatological WVT (Fig. 5d) indicate that an active Indian summer monsoon is associated with a strengthened westerly WVT and monsoon trough, resulting in more water vapor being transported to the central and northern IS through the northern Bay of Bengal. An active rainfall phase in the southeastern TP, on the other hand, corresponds to a northward shift of the monsoonal westerly WVT. In the latter case, water vapor entering the southeastern TP is not only from the northern Bay of Bengal, but also from the northern Arabian Sea. The WVT anomalies to the south of the TP are not exactly opposite between the active phase of central IS rainfall and southeastern TP rainfall. Large WVT anomalies are located slightly farther to the east in the active southeastern TP rainfall phase compared to the active central IS rainfall phase. Other than the detailed differences in their anomaly patterns, the dipole rainfall pattern can be explained by the different pathways of WVT.

The active-break cycles of monsoon rainfall can be linked to the different ISOs. Differences in rainfall and WVT between active and break phases for the 10-20- and 30-60-day ISOs are presented in Fig. 6, based on the filtered rainfall time series. The differences between the active and break phases associated with the ISOs resemble those associated with unfiltered data in general. However, differences associated with 10-20-day ISO are more localized, particularly for CISDR. The magnitudes of the anomalous rainfall and WVT associated with the 10-20-day ISO are somewhat smaller than those associated with the 30-60-day ISO. 



FIG. 5. Composite differences in rainfall ( $\mathrm{mm} \mathrm{day}^{-1}$; shading) and vertically integrated water vapor transport $\left(\mathrm{kg} \mathrm{m}^{-1} \mathrm{~s}^{-1}\right.$; vectors) between active and break phases for (a) PC1 and daily rainfall anomalies averaged in (b) the southeastern Tibetan Plateau and (c) the central Indian subcontinent from 1979 to 2007. (d) Climatology (19792007) of the vertically integrated water vapor transport $\left(\mathrm{kg} \mathrm{m}^{-1} \mathrm{~s}^{-1}\right)$. Only values exceeding $99 \%$ confidence level are shown, and the black dashed lines denote the topographic height of $3000 \mathrm{~m}$.

Both the differences between active and break phases shown in Fig. 6 and the correlations shown in Fig. 4 indicate that the out-of-phase rainfall variation between the central and northern IS and the southeastern TP is tightly linked to both 10-20- and 30-60-day ISOs, with more contribution from the latter.

\section{Characteristics of 10-20- and 30-60-day ISOs}

Comparisons of the differences in rainfall and WVT between active and break phases among PC1, the SETPDR, and the CISDR indicate that PC1 can well represent anomalies associated with SETPDR and CISDR. Thus, the following analyses on the temporal evolution of ISO are based on features associated with PC1.

\section{a. 10-20-day ISO}

Figure 7 shows the evolution of the OLR and $850-\mathrm{hPa}$ wind anomalies over one cycle of the 10-20-day oscillation using lead-lag regressions. The zero-lag OLR anomalies (Fig. 7e) show enhanced convection over the eastern TP but suppressed convection over the northern Bay of Bengal, central and northern IS, and the western TP, representing the active phase of SETPDR. The suppressed convection anomalies over the IS can be traced back to weakly suppressed convection over the western North Pacific on day -8 . It strengthens over the southern South China Sea on day -6 , then moves to the Bay of Bengal on day -4 , finally reaching the southern IS on day -2 , and strengths and shifts northwestward on day 0 . These anomalous features in both the tropics and 

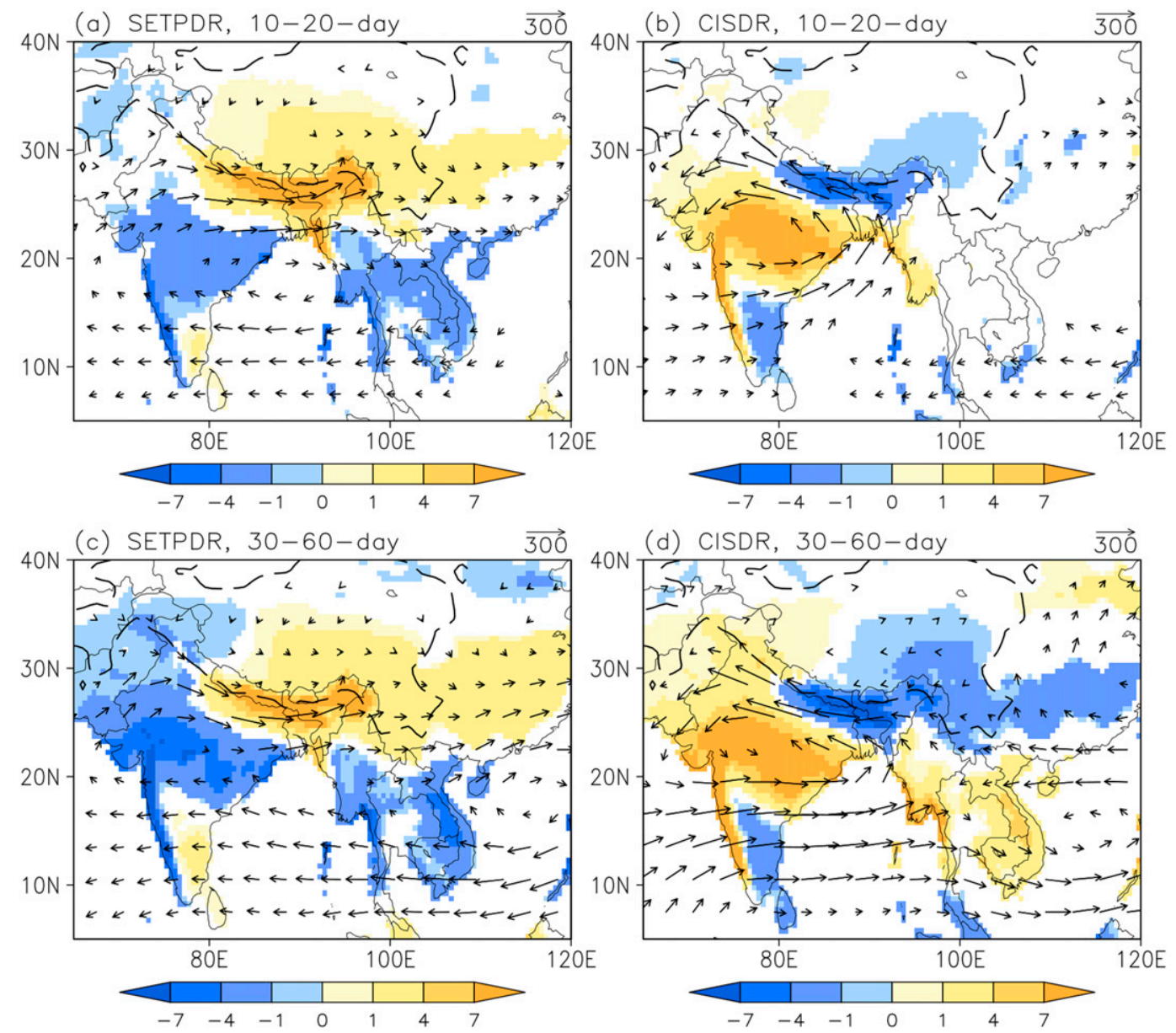

FIG. 6. Composite differences in rainfall $\left(\mathrm{mm} \mathrm{day}^{-1}\right.$; shading) and vertically integrated water vapor transport $\left(\mathrm{kg} \mathrm{m}^{-1} \mathrm{~s}^{-1}\right.$; vectors) between active and break phases for (a),(b) 10-20- and (c),(d) 30-60-day-filtered daily rainfall anomalies averaged in (left) the southeastern Tibetan Plateau and (right) the central Indian subcontinent from 1979 to 2007 . Only values exceeding $99 \%$ confidence level are shown, and the black dashed lines denote the topographic height of $3000 \mathrm{~m}$.

the extratropics are similar to the associated convection anomalies of the 7-20-day oscillation over the central TP identified by Fujinami and Yasunari (2004). In general, the suppressed convection anomalies in the tropics exhibit a westward propagation from the western North Pacific $($ day -8$)$ to the northwestern IS (day 0), which can be seen more clearly in the evolution of the regressed OLR averaged between $0^{\circ}$ and $20^{\circ} \mathrm{N}$ (Fig. 8a). The westward propagation of 10-20-day ISO can be understood as a convectively coupled equatorial Rossby waves under the mean monsoon flow (Chatterjee and Goswami 2004; Kikuchi and Wang 2009). The westward propagation of the suppressed convection is always accompanied by a local anticyclone, which can be excited by the diabatic cooling of the suppressed convection according to the Gill model (Gill 1980) and numerical model results (e.g., Jiang and Ting 2017).
On the other hand, a southeastward propagation of convection anomalies can be seen over the extratropics from the Caspian Sea to the SETP over a cycle, which is associated with a wave train. Fujinami and Yasunari (2004) reported that the wave train can affect convection over the TP by modulating the upper-tropospheric ridge or trough to the west of the $\mathrm{TP}$, which affects the dynamical and thermodynamical conditions over the TP; an anomalous upper-level trough (ridge) to the west of the plateau favors enhanced (suppressed) convection over the TP. As shown in Fig. 7, enhanced convection over the TP is always accompanied by negative geopotential height anomalies to the west. The suppressed convection from the tropics and extratropics meets over the western TP on day -2 , and the extratropical component continues its eastward movement to eastern China on day 8 . The 

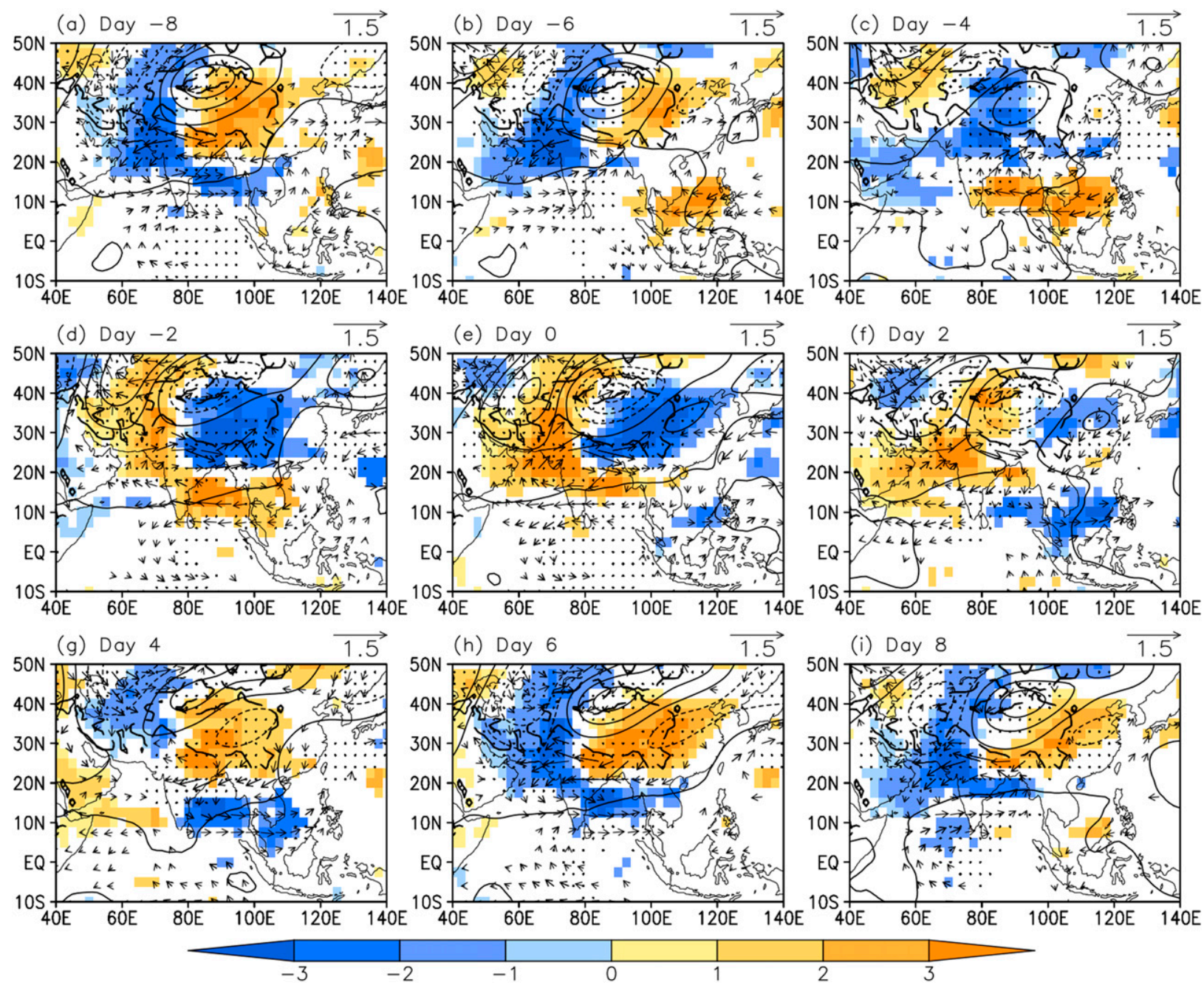

FIG. 7. Patterns of regression of 29-yr (1979-2007) JJAS 10-20-day-filtered OLR ( $\mathrm{W} \mathrm{m}^{-2}$; shading), 850-hPa wind ( $\mathrm{m} \mathrm{s}^{-1}$; vectors), and 200-hPa geopotential height (dgpm; contours) on 10-20-day-filtered PC1 from (a) a lag of 8 days (day -8) to (i) a lead of 8 days (day 8). Only values exceeding $95 \%$ confidence level are shown. Stippling indicates the value of the geopotential height exceeding $95 \%$ confidence level. The black dashed lines denote the topographic height of $3000 \mathrm{~m}$.

eastward propagation of the extratropical signal can be clearly seen in Fig. $8 \mathrm{~b}$ for both the enhanced and suppressed convections averaged over the latitude bands of $25^{\circ}-40^{\circ} \mathrm{N}$.

It is worth noting that the significant suppressed convection over the eastern TP on day -6 disappears on day -4 , and is replaced by significant enhanced convection on day -2 . At the same time, the suppressed convection in the tropics moves to the Bay of Bengal and strengthens there. As the suppressed convection over the Bay of Bengal is accompanied by a local anomalous anticyclone, which favors more water vapor to the southeastern TP (Jiang et al. 2016), the rapid development of enhanced convection over the eastern TP on day -2 can be attributed to both the eastward movement of the enhanced convection over the western TP and the westward propagation of suppressed convection to the south of the TP. Opposite processes can also be seen from days 2 to 6 , where enhanced tropical convection over the Bay of Bengal suppresses moisture transport to eastern TP, favoring the development of suppressed convection there on days 4 and 6 .

Figure 9 depicts the lead-lag regression of $200-\mathrm{hPa}$ geopotential height on $\mathrm{PC} 1$ from $\mathrm{PC} 1$ lagging by 8 days to leading by 8 days. A wavelike pattern can be seen in midlatitudes for all time lags and it shows an eastward propagation. Of note is that only the anomalous centers from the Black Sea to eastern China show continuous southeastward propagation from day -8 to day 8 , which is consistent with the evolution of regressed OLR averaged between $25^{\circ}$ and $40^{\circ} \mathrm{N}$ (Fig. 8b). 

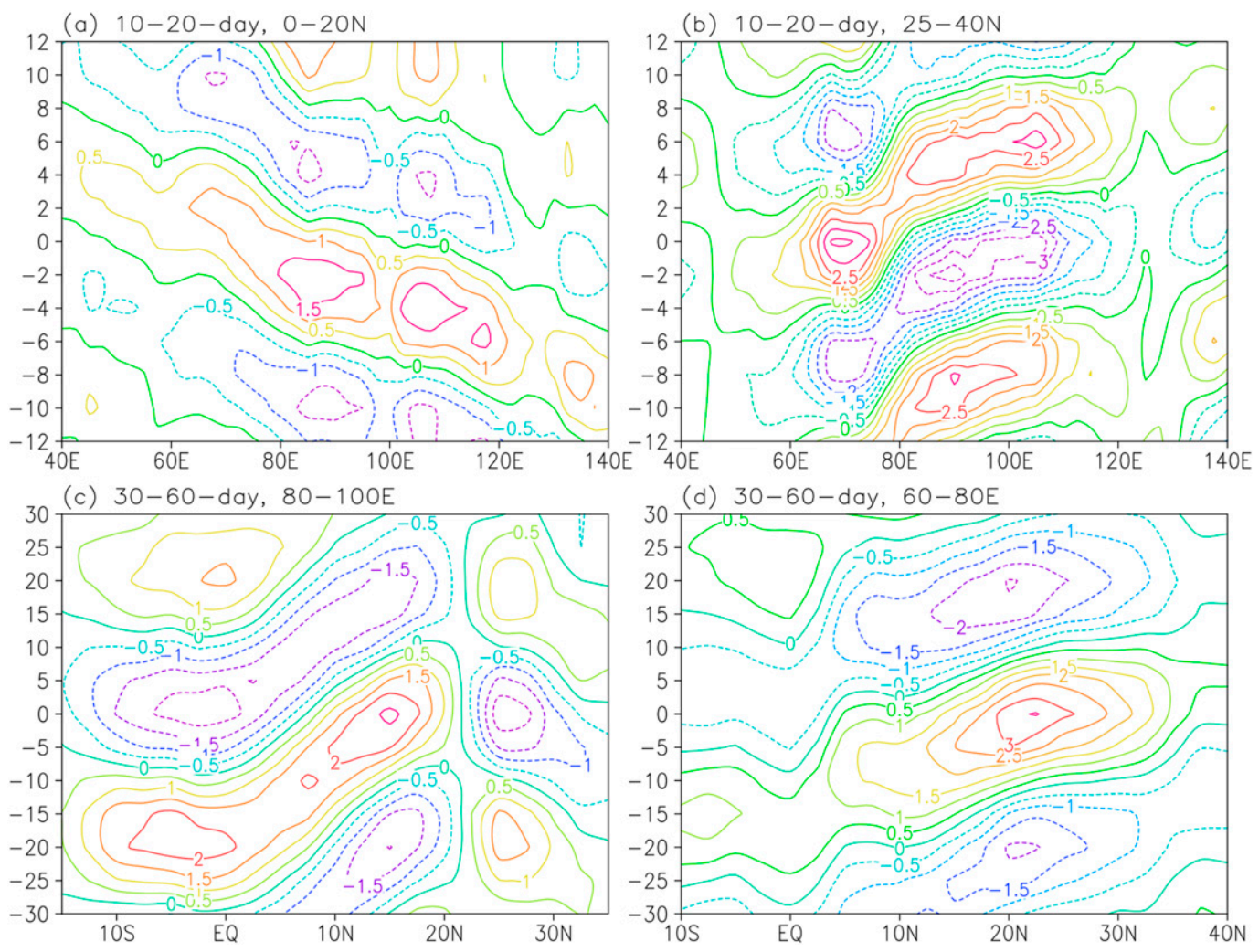

FIG. 8. Lead-lag regression of filtered OLR $\left(\mathrm{W} \mathrm{m}^{-2}\right)$ on filtered PC1: (a) averaged 10-20-day-filtered OLR between $0^{\circ}$ and $20^{\circ} \mathrm{N}$, (b) averaged $10-20$-day-filtered OLR between $25^{\circ}$ and $40^{\circ} \mathrm{N}$, (c) averaged 30-60-day-filtered OLR between $80^{\circ}$ and $100^{\circ} \mathrm{E}$, and (d) averaged 30-60-day-filtered OLR between $60^{\circ}$ and $80^{\circ} \mathrm{E}$. The unit of the $x$ axis for all the panels is days and negative (positive) values indicate that OLR leads (lags) PC1.

The wave train may be interpreted as a Rossby wave propagation along the upper-level westerly jet stream (Terao 1998; Enomoto et al. 2003). Hu et al. (2016) reported that the 7-20-day ISO of rainfall over the eastern TP is related to a Rossby wave train stretching from the eastern Atlantic to southern China.

To further examine the link between tropical and midlatitude convection anomalies and their contribution to the dipole pattern, we identify individual 10-20-day ISO events and their temporal evolution next. The normalized 10-20-day-filtered PC1 is used to identify the 10-20-day ISO event of the dipole pattern, which is defined by anomalous peak values in both active and break phases over a cycle higher than one standard deviation. According to this criterion, there are 113 10-20-day ISO events during June-September from 1979 to 2007.

Following previous studies (e.g., Fujinami and Yasunari 2004), an ISO event is comprised of eight phases, and phases 3 and 7 correspond to the positive and negative extremes in $\mathrm{PC} 1$, respectively. We analyze the evolution of anomalies of 10-20-day-filtered OLR,
850-hPa wind, and 200-hPa geopotential height for each event and find that the westward propagation of tropical convection and the southeastward propagation of convection in the midlatitudes do not always occur at the same time. According to the features of propagation of anomalies, the 113 events are categorized into three types subjectively. Type I includes 56 events $(50 \%)$, featuring westward propagation of convection in the tropics and southeastward propagation of convection in the midlatitudes; type II has 31 events $(28 \%)$, featuring only westward propagation of significant convection in the tropics; and type III has 26 events (23\%), featuring only southeastward propagation of significant convection in the midlatitudes.

The evolution of the composite 10-20-day-filtered OLR, 850-hPa wind, and 200-hPa geopotential height for type I (figure not shown) are similar to those in Fig. 7, while they are different from those for types II and III, which are shown in Figs. 10 and 11, respectively. It can be seen that propagation of significant anomalies is found only in the tropics for type II (Fig. 10). On the other hand, propagation of significant anomalies is 

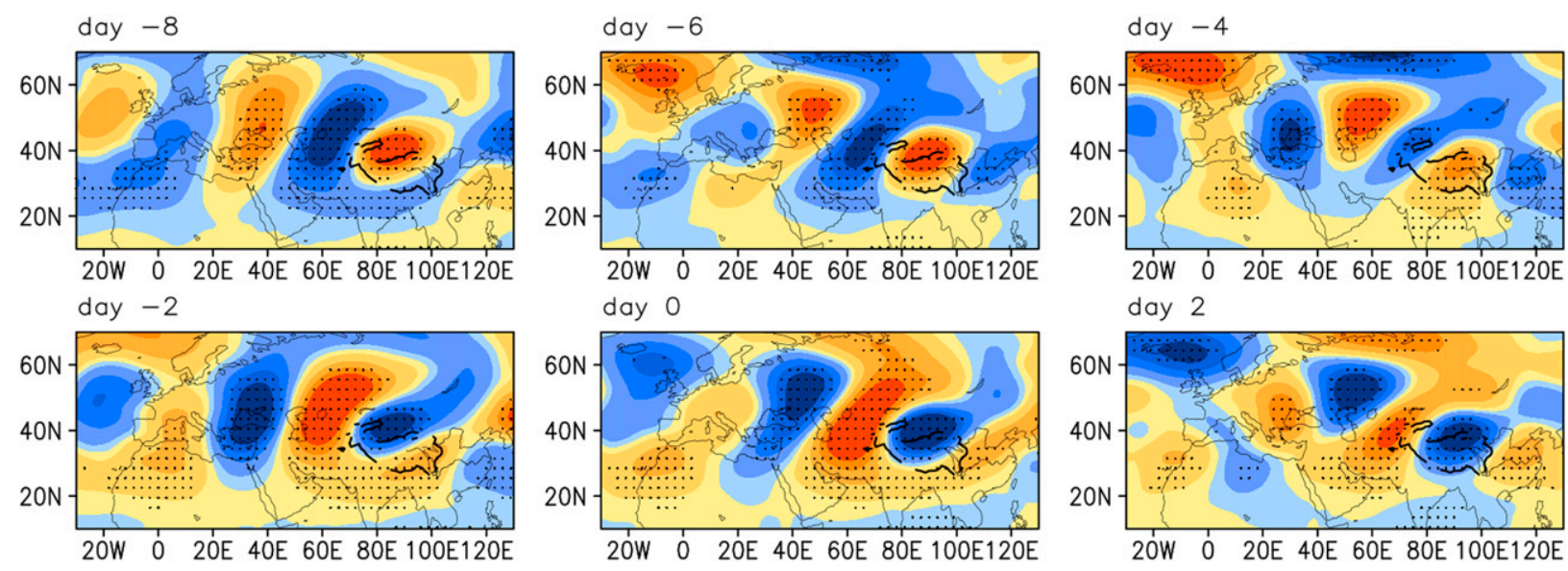
day 0

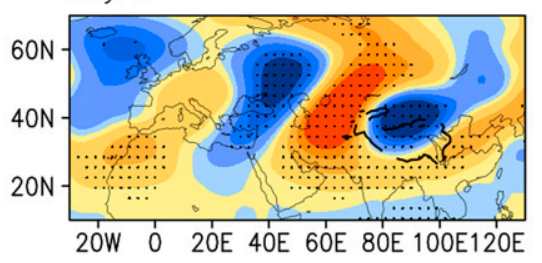
day 2


day 4
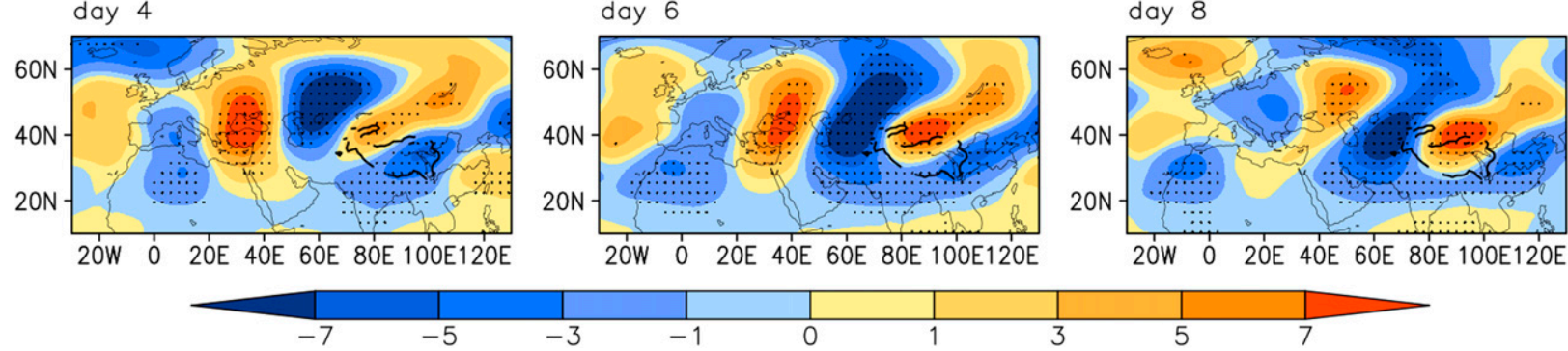

FIG. 9. As in Fig. 7, but for 200-hPa geopotential height (dgpm).

found only in the midlatitudes for type III (Fig. 11). Comparison between Figs. 10 and 11 indicates that the dipole pattern is different between types II and III. It is a predominantly north-south dipole for type II but an eastwest dipole for type III, together forming the dipole in Fig. 1b. The propagation of the 10-20-day ISO in the midlatitudes cannot cause significant anomalies to the south of TP (Fig. 10); rather, the out-of-phase relationship in convection anomalies between the central IS and southeastern TP is mostly contributed by the 10-20-day ISO in the tropics (Fig. 10). When the convection anomalies of the 10-20-day ISO propagate to the Bay of Bengal and the IS, opposite convection anomalies are found over the southern TP simultaneously, forming a dipole pattern (Fig. 10).

\section{b. 30-60-day ISO}

Similar lead-lag regression analysis is also performed for the 30-60-day-filtered OLR anomalies in Fig. 12. The zero-lag OLR anomalies associated with the 30-60-day ISO of PC1 shows enhanced convection from the eastern TP to Japan, and in the eastern tropical Indian Ocean, but a band of suppressed convection from the northwestern IS to the western North Pacific (Fig. 12e). The suppressed convection is associated with a large-scale anticyclonic flow locally and originates from suppressed convection over the tropical eastern Indian Ocean (day -20), which propagates northwestward to northwestern IS and northeastward to the western North Pacific. It is interesting that the northward-propagating OLR anomaly from the equatorial Indian Ocean does not seem to reach the southern TP, but the zonal wind anomalies seem to be able to move northward up to the foothill of the Himalayas from day -20 to day 5 . The northward propagation of the 30-60-day ISO can be seen more clearly from the regressed OLR anomalies averaged over $80^{\circ}$ $100^{\circ} \mathrm{E}$ as a function of lag time (Fig. 8c), which can be explained by a combination of a vertical wind shear mechanism and a moisture-convection feedback mechanism (e.g., Jiang et al. 2004; Goswami 2012). Air-sea interactions also modulate the northward propagation of the 30-60-day ISO (e.g., Fu et al. 2003, 2007).

Figure $8 \mathrm{c}$ shows that the convection over the southeastern TP $\left(20^{\circ}-30^{\circ} \mathrm{N}\right)$ varies out of phase with that between $10^{\circ}$ and $20^{\circ} \mathrm{N}$, and thus the convection anomaly over the southeastern TP is not a result of the northward propagation of the 30-60-day ISO. Instead, it may be interpreted as a response to convection anomalies over the Bay of Bengal and the central IS, where enhanced convection could suppress convection over the southeastern TP (Jiang et al. 2016; Jiang and Ting 2017).

The enhanced convection over the southeastern TP on day 0 can be traced back to the enhanced convection 
(a) Phase 1

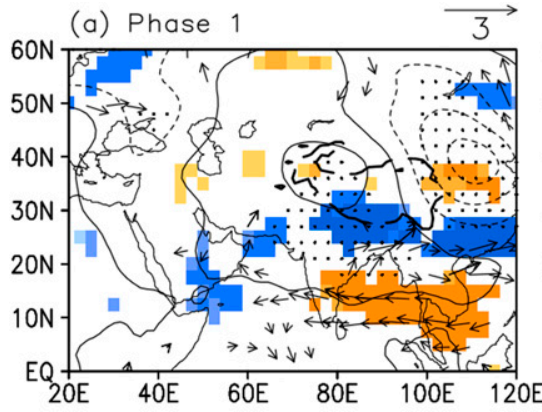

(d) Phase 4

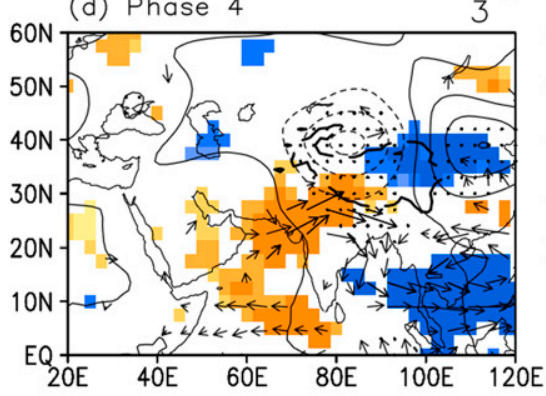

(g) Phase 7

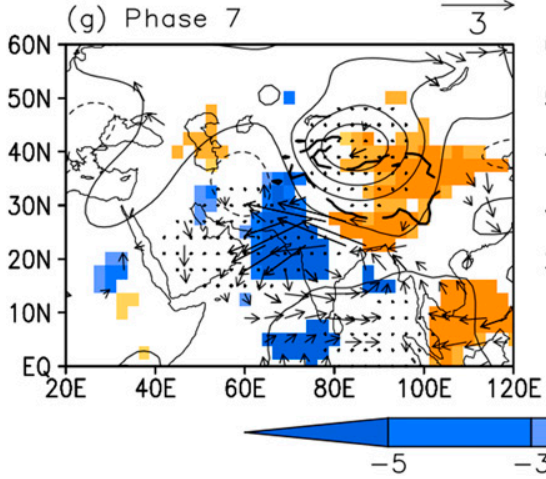

(b) Phase 2

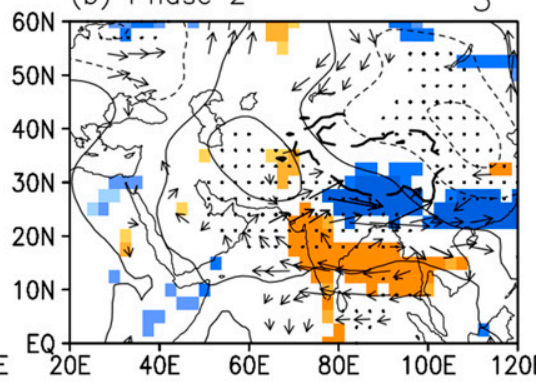

(e) Phase 5



(c) Phase 3

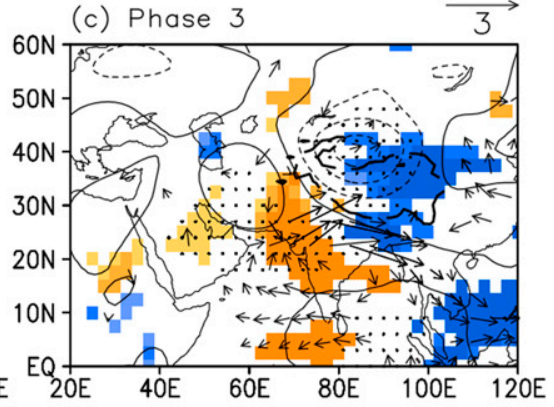

(f) Phase 6

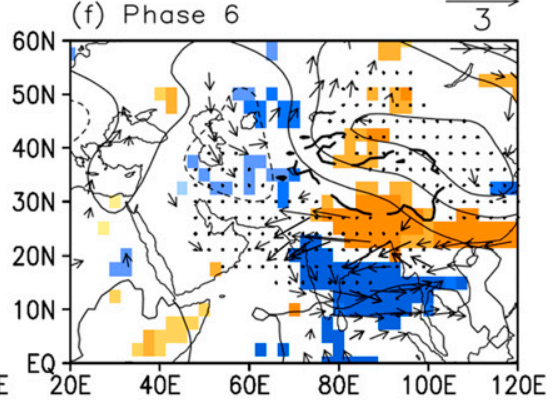

(h) Phase 8 3



FIG. 10. Composite anomalies of 10-20-day-filtered OLR ( $\mathrm{W} \mathrm{m}^{-2}$; shading), 850-hPa wind ( $\mathrm{m} \mathrm{s}^{-1}$; vectors), and 200-hPa geopotential height (dgpm; contours) for type II 10-20-day ISO of PC1. Only values exceeding 95\% confidence are shown for OLR and 850-hPa wind. Stippling indicates the value of the geopotential height exceeding $95 \%$ confidence level. The black dashed lines denote the topographic height of $3000 \mathrm{~m}$.

over the western TP on day -15 , which propagates southeastward. Based on the evolution of convection anomalies from day -20 to day -15 , and from day 15 to day 20, the convection anomalies over the western TP can be regarded as a result of the northward propagation of convection originated from the tropical eastern Indian Ocean. As shown in Fig. 8d, the 30-60-day ISO in the longitude band between $60^{\circ}$ and $80^{\circ} \mathrm{E}$ can propagate to around $35^{\circ} \mathrm{N}$, while it only reaches to around $20^{\circ} \mathrm{N}$ in the longitudes between $80^{\circ}$ and $100^{\circ} \mathrm{E}$ (Fig. $8 \mathrm{c}$ ).

Of note is that the enhanced convection over the southeastern TP strengthens rapidly from day -10 to day -5 , which is accompanied by the suppressed convection moving from the southern IS and the southern Bay of Bengal to the central and northwestern IS and the central Bay of Bengal. The enhanced convection over the southeastern TP further develops as the suppressed convection and associated anomalous anticyclone to the south strengthen at day 0 . Rapid development of enhanced convection from day -10 to day -5 can be also seen in southern China, which may be ascribed to the northward propagation of the anomalous anticyclone associated with suppressed convection over the western North Pacific.

As the 10-20-day ISO of the dipole pattern is associated with the propagation of wave train in the midlatitudes, we also examine the $200-\mathrm{hPa}$ geopotential anomalies related to the 30-60-day ISO of PC1 from a lag of 20 days to a lead of 20 days. While there is a wave train associated with the zero lag with alternate sign centers from the eastern North Atlantic southeastward to the south of TP, there is no obvious wave trains associated 
(a) Phase 1

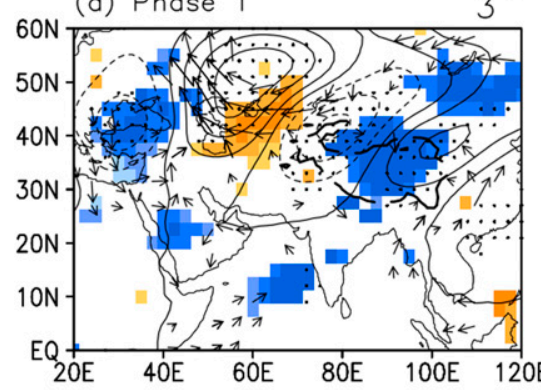

(d) Phase 4



(b) Phase 2

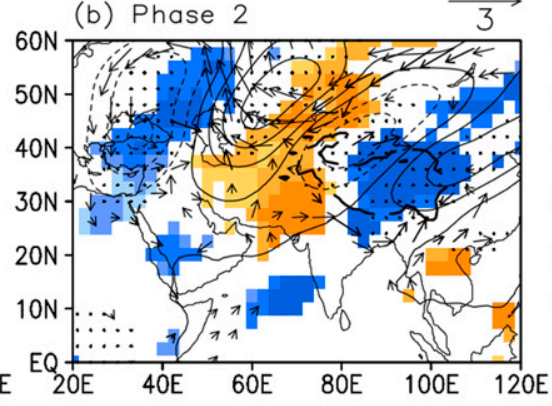

(e) Phase 5

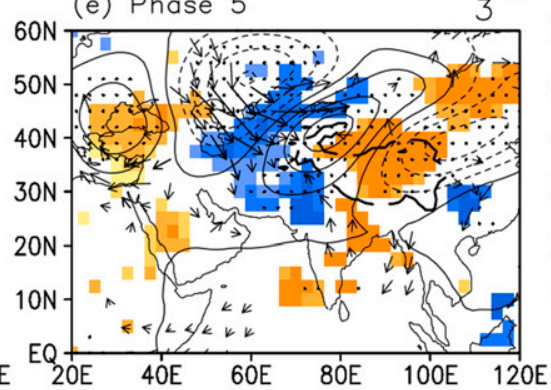

(h) Phase 8

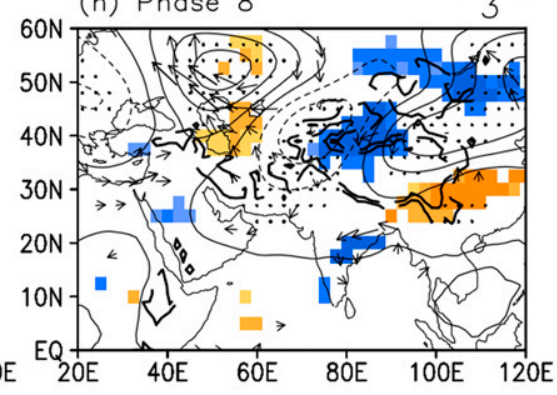

(c) Phase 3

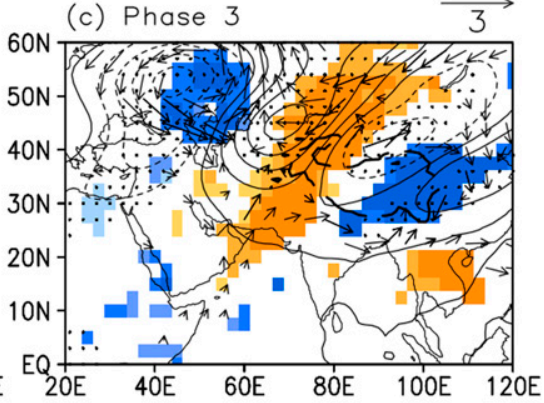

(f) Phase 6

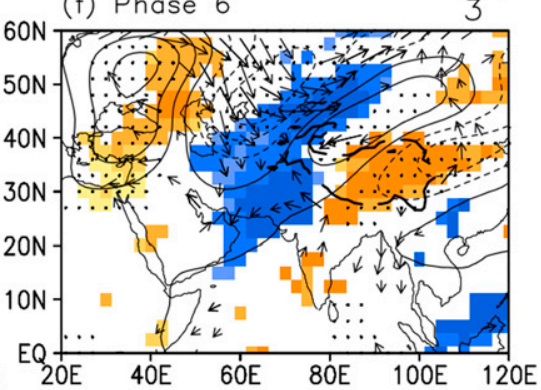

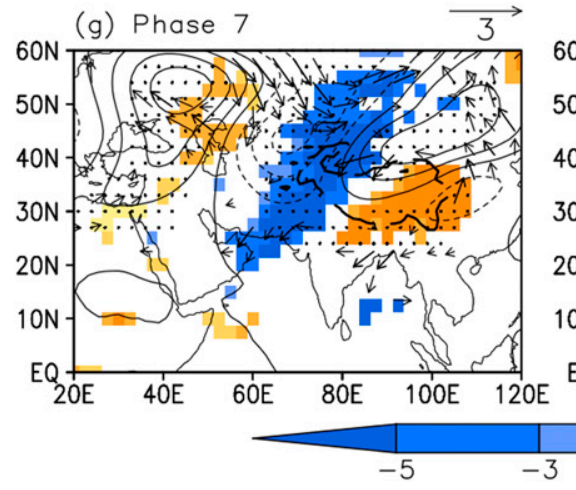
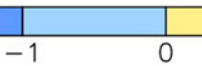

FIG. 11. As in Fig. 10, but for type III 10-20-day ISO of PC1.

with 30-60-day ISO of PC1 (Fig. 12). Comparison of Figs. 7 and 12 indicate that the relationship of $200-\mathrm{hPa}$ geopotential height anomalies with local convection anomalies over the TP is different between the 10-20and 30-60-day ISOs. Significant 200-hPa geopotential height anomalies tend to be located between two significant convection anomalies for the 10-20-day ISO, while located with local convection anomalies for the 30-60-day ISO. For example, enhanced convection is accompanied by increase in geopotential height in the upper troposphere at day 0 (Fig. 12). According to previous studies (e.g., Jiang and Ting 2017), the uppertropospheric geopotential height may be a response to the diabatic heating of local enhanced convection. This feature indicates that the convection anomalies over the TP associated with the 30-60-day ISO may not be a response to the wavelike geopotential height anomalies in the upper troposphere.
The above analyses indicate that the northward propagation of convection anomalies originating from the tropical eastern Indian Ocean may cause the dipole rainfall pattern as it moved to the central Bay of Bengal and the central and northern IS. The dipole rainfall pattern can further be strengthened by the convection anomalies propagated from the western TP to the southeastern TP, which can be regarded as a result of the northward propagation of convection anomalies over the northwestern IS in the previous cycle. The 30-60-day ISO of the dipole pattern is not obviously associated with propagation of wave train in the midlatitudes in terms of $200-\mathrm{hPa}$ geopotential height anomalies.

To quantitatively reflect the relationship between the dipole pattern and the northward propagation of the 3060-day ISO, we calculated the correlation of the 30-60-dayfiltered PC1 with the boreal summer tropical intraseasonal oscillation index proposed by Kikuchi et al. (2012) 



FIG. 12. As in Fig. 7, but for 30-60-day-filtered values from (a) a lag of 20 days to (i) a lead of 20 days.

(available at http://iprc.soest.hawaii.edu/users/kazuyosh/ Bimodal_ISO.html), which is represented by principal components of the first two modes of an extended EOF analysis with -10 - and -5-day lags applied to the 2590-day-filtered OLR data in the entire tropics between $30^{\circ} \mathrm{S}$ and $30^{\circ} \mathrm{N}$ from June to August (Kikuchi et al. 2012). The two PCs are highly correlated with the 30-60-dayfiltered PC1 with different time lag, with the highest mean correlation coefficients from 1979 to 2007 of 0.41 and 0.50 , respectively.

\section{Possible contribution of the ISOs of rainfall to interannual variability of July-August mean rainfall}

Jiang and Ting (2017) reported that the dipole rainfall pattern also exists in the interannual variability of seasonal-mean rainfall, which can be seen from the first
EOF mode of July-August mean rainfall (Fig. 1d). Thus, the intraseasonal variability and interannual variability of rainfall across the IS and the TP share a common mode of spatial covariation.

To illustrate the relationship of the dipole rainfall pattern on intraseasonal time scale with that on interannual time scale, we calculate the difference in number of days between active and break phases of PC1. Figure 13 shows the normalized PC1 of the interannual variability of July-August mean rainfall (black) and the number of days between active and break phases of the 30-60-day-filtered PC1 (red). They vary in phase in most years, with a correlation coefficient of 0.62 , which is close to the correlation coefficient with unfiltered daily PC1 (0.66; Table 1$)$. The PC1 of July-August mean rainfall is also significantly correlated with the number of days between active and break phases of SETPDR and CISDR for both raw and 


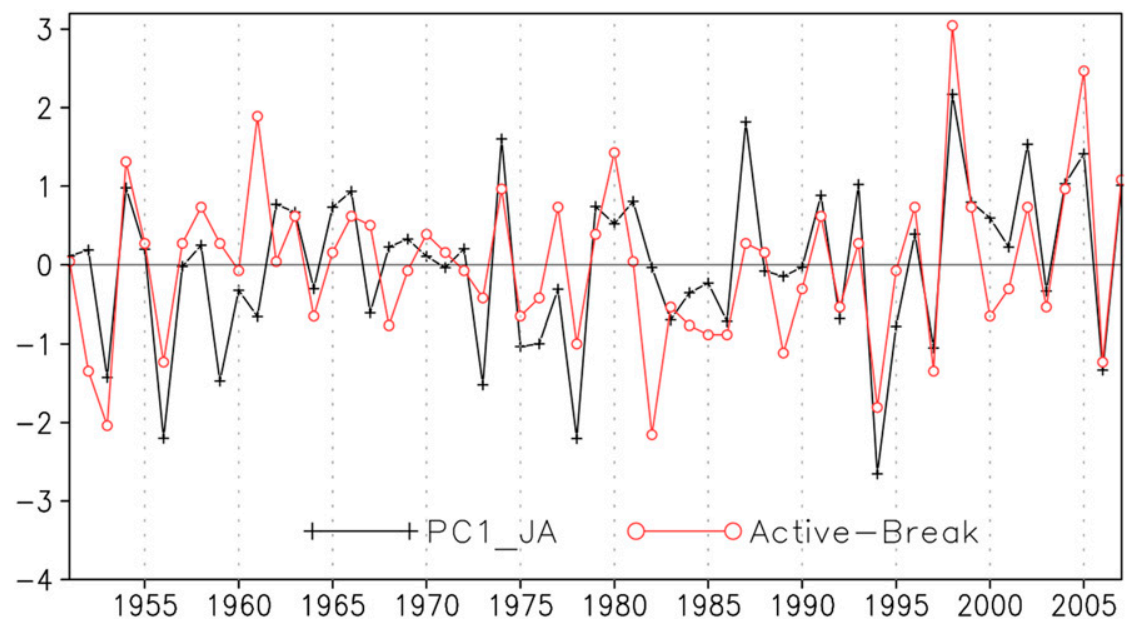

FIG. 13. Normalized principal component (black curves with plus signs) of the first EOF mode when applied to temporal correlation matrix of July-August mean rainfall anomalies from 1951 to 2007, and normalized number of days between active and break phases of 30-60day-filtered PC1 (red curves with open circles).

30-60-day-filtered values, but it is not significantly correlated with 10-20-day-filtered values (Table 1). This indicates that more occurrences of the break phase of the Indian monsoon rainfall or positive phase of the southeastern TP rainfall could result in a positive phase of the dipole pattern in July-August mean rainfall. The intraseasonal contribution to seasonalmean dipole mode is largely due to the 30-60-day oscillation.

Fujinami et al. (2011) reported that interannual variability of rainfall over Bangladesh, to the south of $\mathrm{TP}$, is positively correlated with the variance of intraseasonal rainfall variability. Table 1 lists the correlation coefficient between PC1 of JA mean rainfall and intraseasonal variance of SETPDR, CISDR, and $\mathrm{PC} 1$. The PC1 of JA mean rainfall is negatively and significantly correlated with intraseasonal variance of PC1, indicating that the dipole pattern tends to form when the ISOs are weak. This is different from that in Bangladesh. Qi et al. (2008) also reported that all-India summer monsoon rainfall is negatively correlated with the intensity of the 30-60-day ISO.
As the intraseasonal variability of rainfall is dominated by the 7-25-day ISO over Bangladesh but the 30-60-day ISO over India, the contribution of ISOs to total rainfall might be affected by the dominant ISO.

The above results indicate that the ISOs of the dipole contribute to the dipole pattern of JulyAugust mean rainfall anomalies, especially the 30 60-day ISO. Jiang and Ting (2017) reported that the dipole pattern of rainfall across the IS and the TP on interannual time scales exhibits month-to-month variations. It is strong in July and August, but weak in June and September. Indeed, the correlations between the two dipole rainfall centers, the SETPDR and CISDR, on 30-60-day time scales are also stronger in July and August (Fig. 6), thus further confirming the contribution of the intraseasonal dipole to the interannual dipole. In addition, the dominant contribution of the 30-60-day ISO of rainfall anomalies to the dipole pattern of JulyAugust mean rainfall anomalies is also supported by the fact that they are associated with similar large-scale

TABLE 1. Correlation coefficients of the first principal component of an EOF analysis applied to a temporal correlation matrix of the interannual variation of July-August mean rainfall anomalies from 1951-2007 with the July-August mean number of days between active and break spells (frequency) and intraseasonal variance (amplitude) of PC1, SETPDR, and CISDR for raw, 10-20-day-filtered, and 3060 -day-filtered daily rainfall. Values in italic and boldface fonts exceed the confidence levels of $95 \%$ and $99.9 \%$, respectively.

\begin{tabular}{|c|c|c|c|c|c|c|}
\hline & \multicolumn{2}{|c|}{$\mathrm{PC} 1$} & \multicolumn{2}{|c|}{ SETPDR } & \multicolumn{2}{|c|}{ CISDR } \\
\hline & Frequency & Amplitude & Frequency & Amplitude & Frequency & Amplitude \\
\hline Raw & 0.66 & 0.40 & 0.57 & 0.25 & -0.43 & -0.20 \\
\hline 30-60-day ISO & 0.62 & 0.35 & 0.53 & 0.02 & -0.24 & 0.02 \\
\hline 10-20-day ISO & 0.20 & 0.40 & 0.0 & -0.06 & 0.16 & -0.15 \\
\hline
\end{tabular}


anomalies in rainfall and circulation [cf. Fig. 5 herein and Fig. 2 in Jiang and Ting (2017)].

\section{Summary and discussion}

In this study, we investigate the possible link between the Indian summer monsoon and the TP in terms of rainfall variability on intraseasonal time scales. The most dominant mode of intraseasonal variabilities of JJAS daily rainfall across the IS and the TP features a dipole pattern, with significant out-of-phase relationship between the southeastern TP and the central and northern IS. This dipole pattern exhibits ISOs with periods of 10-20 and 30-60 days, and the out-of-phase relationship is stronger for the 30-60-day ISO.

As the first EOF mode only explains $9.3 \%$ of total variance and is not significantly separated from other modes, we also calculate correlation of the regionally averaged rainfall for the SETP and the CIS with rainfall over the entire region for raw and filtered values. The correlation patterns confirm the existence of the dipole pattern. The first mode of an EOF analysis applied to temporal correlation matrix of JJAS 10-20- and 3060-day-filtered daily rainfall anomalies also exhibits a dipole pattern. In addition, both the 10-20- and 30 60-day ISOs explains a large portion the total daily rainfall variance. The percentage of variance of the 10 20 -day ISO is over $32 \%$ in most of the study region, and the percentage of variance of the 30-60-day ISO is over $16 \%$ in the core regions in this study.

To highlight features associated with the dipole rainfall pattern, we further investigate characteristics of active and break spells of the dipole rainfall pattern, as well as rainfall over the southeastern TP and the central IS. An active spell of rainfall in central IS is accompanied by a break spell of rainfall in the southeastern TP, and vice versa. An active spell of rainfall in the central IS (southeastern TP) is associated with the strengthening (northward shift) of Indian monsoon water vapor transport, resulting in more water vapor being transported to the central and northern IS (southeastern TP) thereby more rainfall there. Active or break spells of rainfall related to the 30-60-day ISO is associated with atmospheric anomalies on a larger spatial scale compared to those associated with the 10-20-day ISO, especially for central IS rainfall.

Active and break spells of the dipole rainfall pattern are associated with different atmospheric processes for the 10-20- and 30-60-day ISOs. For the 10-20-day ISO, the active and break spells are caused by a westward propagation of convection anomalies originated from the tropical western North Pacific and a southeastwardpropagating atmospheric disturbance originated from the Black Sea over the midlatitudes. About half of the anomalies from the tropics and midlatitudes are phase locked when getting to the dipole regions, causing an outof-phase relationship. On the other hand, active and break spells of the dipole rainfall pattern associated with the 30-60-day ISO are mostly caused by northward propagation of convection anomalies originated from the eastern equatorial Indian Ocean. Tropical convection anomalies can impact the dipole rainfall pattern directly when they propagate into the Bay of Bengal and the central and northern IS or strengthen the dipole rainfall pattern indirectly by propagating into the western TP and then moving eastward. It is worth noting that when convection is enhanced over the Bay of Bengal and the central and northern IS, convection tends to be suppressed over the southeastern TP at the same time. This simultaneous relationship suggests that convection anomalies between the central and northern IS and the southeastern TP can interact with each other, consistent with that reported by Jiang and Ting (2017) on interannual time scales. Possible mechanisms responsible for the propagation of ISOs in the tropics and extratropics have been investigated by previous studies (e.g., Jiang et al. 2004; Goswami 2012; Wang and Duan 2015; Hu et al. 2016). However, how ISOs propagate from the northwestern IS to the western TP remains unclear, which warrants further studies.

The dipole pattern of rainfall anomalies on intraseasonal time scales also exists on interannual time scales, especially for July-August mean rainfall. This is due to the different frequency of occurrence of the active and break phases of the dipole pattern on intraseasonal time scales that can contribute substantially to the dipole pattern in JulyAugust mean rainfall. When there are more active phases than break phases of the dipole rainfall during one particular season, the seasonal-mean rainfall anomalies tend to show positive phase of the dipole pattern, and vice versa. The contribution of ISOs to interannual variability of JulyAugust mean rainfall comes mostly from the 30-60-day ISO. Jiang and Ting (2017) reported that the dipole rainfall pattern on interannual time scales also can be caused by sea surface temperature anomalies in the southeastern tropical Indian Ocean. The number of days between active and break phases of PC1 is positively correlated with sea surface temperature anomalies in this region, indicating that the SST anomalies may affect the dipole pattern by modulating the 30-60-day ISO. The southeastern tropical Indian Ocean is also the region where northward propagation of the 30-60-day ISO is initialized. How SST anomalies in this region affect the asymmetry of the dipole pattern deserves further study.

Acknowledgments. This study was jointly supported by the National Natural Science Foundation of China (Grants 91337107, 91637208, and 41661144019), Applied 
Basic Research Program of Sichuan Province (18YYJC0601), and the Basic Research and Operation Program of the CMA Institute of Plateau Meteorology (BROP 201514). MT is supported by NSF Grant AGS 1607348.

\section{REFERENCES}

Annamalai, H., and J. M. Slingo, 2001: Active/break cycles: Diagnosis of the intraseasonal variability of the Asian summer monsoon. Climate Dyn., 18, 85-102, https://doi.org/10.1007/ s003820100161.

Chatterjee, P., and B. N. Goswami, 2004: Structure, genesis and scale selection of the tropical quasi-biweekly mode. Quart. J. Roy. Meteor. Soc., 130, 1171-1194, https://doi.org/ 10.1256/qj.03.133.

Chen, W., 1982: Fluctuations in Northern Hemisphere $700 \mathrm{mb}$ height field associated with the Southern Oscillation. Mon. Wea. Rev., 110, 808-823, https://doi.org/10.1175/ 1520-0493(1982)110<0808:FINHMH>2.0.CO;2.

Davis, R. E., 1976: Predictability of sea surface temperature and sea level pressure anomalies over the North Pacific Ocean. J. Phys. Oceanogr., 6, 249-266, https://doi.org/ 10.1175/1520-0485(1976)006<0249:POSSTA > 2.0.CO;2.

Dee, D. P., and Coauthors, 2011: The ERA-Interim reanalysis: Configuration and performance of the data assimilation system. Quart. J. Roy. Meteor. Soc., 137, 553-597, https://doi.org/ 10.1002/qj.828.

Ding, Q. H., and B. Wang, 2007: Intraseasonal teleconnection between the summer Eurasian wave train and the Indian monsoon. J. Climate, 20, 3751-3767, https://doi.org/10.1175/ JCLI4221.1.

Ding, R. Q., J. P. Li, and K.-H. Seo, 2010: Predictability of the Madden-Julian oscillation estimated using observational data. Mon. Wea. Rev., 138, 1004-1013, https://doi.org/ 10.1175/2009MWR3082.1.

- - — boreal summer and winter intraseasonal oscillations from observations. Mon. Wea. Rew., 139, 2421-2438, https://doi.org/10.1175/2011MWR3571.1.

Duchon, C. E., 1979: Lanczos filtering in one and two dimensions. J. Appl. Meteor., 18, 1016-1022, https://doi.org/ 10.1175/1520-0450(1979)018<1016:LFIOAT>2.0.CO;2.

Enomoto, T., B. J. Hoskins, and Y. Matsuda, 2003: The formation mechanism of the Bonin high in August. Quart. J. Roy. Meteor. Soc., 129, 157-178, https://doi.org/10.1256/qj.01.211.

Fu, X., B. Wang, T. Li, and J. McCreary, 2003: Coupling between northward-propagating, intraseasonal oscillations and sea surface temperature in the Indian Ocean. J. Atmos. Sci., 60, 1733-1753, https://doi.org/10.1175/1520-0469(2003)060<1733: CBNIOA $>2.0 . \mathrm{CO} ; 2$.

$\longrightarrow,-$ D. E. Waliser, and L. Tao, 2007: Impact of atmosphereocean coupling on the predictability of monsoon intraseasonal oscillations. J. Atmos. Sci., 64, 157-174, https://doi.org/ 10.1175/JAS3830.1.

Fujinami, H., and T. Yasunari, 2004: Submonthly variability of convection and circulation over and around the Tibetan Plateau during the boreal summer. J. Meteor. Soc. Japan, 82, 1545-1564, https://doi.org/10.2151/jmsj.82.1545.

- and Coauthors, 2011: Characteristic intraseasonal oscillation of rainfall and its effect on interannual variability over Bangladesh during boreal summer. Int. J. Climatol., 31, 1192-1204, https://doi.org/10.1002/joc.2146.
_, T. Yasunari, and A. Morimoto, 2014: Dynamics of distinct intraseasonal oscillation in summer monsoon rainfall over the Meghalaya-Bangladesh-western Myanmar region: Covariability between the tropics and mid-latitudes. Climate Dyn., 43, 2147-2166, https://doi.org/10.1007/s00382-0132040-1.

Gadgil, S., 2003: The Indian monsoon and its variability. Annu. Rev. Earth Planet. Sci., 31, 429-467, https://doi.org/10.1146/ annurev.earth.31.100901.141251.

Gill, A., 1980: Some simple solutions for heat-induced tropical circulations. Quart. J. Roy. Meteor. Soc., 106, 447-462, https:// doi.org/10.1002/qj.49710644905.

Goswami, B. N., 2012: South Asian monsoon. Intraseasonal Variability in the Atmosphere-Ocean Climate System, 2nd ed., W. K. M. Lau and D. E. Waliser, Eds., Springer, 21-72.

—_, and R. S. Ajayamohan, 2001: Intraseasonal oscillations and interannual variability of the Indian summer monsoon. J. Climate, 14, 1180-1198, https://doi.org/10.1175/1520-0442 (2001)014<1180:IOAIVO>2.0.CO;2.

—_, and P. K. Xavier, 2005: Dynamics of "internal" interannual variability of the Indian summer monsoon in a GCM. J. Geophys. Res., 110, D24104, https://doi.org/ 10.1029/2005JD006042.

—, R. S. Ajayamohan, P. K. Xavier, and D. Sengupta, 2003: Clustering of synoptic activity by Indian summer monsoon intraseasonal oscillations. Geophys. Res. Lett., 30, 1431, https://doi.org/10.1029/2002GL016734.

Hatsuzuka, D., and H. Fujinami, 2017: Effects of the South Asian monsoon intraseasonal modes on genesis of low pressure systems over Bangladesh. J. Climate, 30, 2481-2499, https:// doi.org/10.1175/JCLI-D-16-0360.1.

Hoyos, C. D., and P. J. Webster, 2007: The role of intraseasonal variability in the nature of Asian monsoon precipitation. J. Climate, 20, 4402-4424, https://doi.org/10.1175/JCLI4252.1.

Hu, W., A. Duan, Y. Li, and B. He, 2016: The intraseasonal oscillation of eastern Tibetan Plateau precipitation in response to the summer Eurasian wave train. J. Climate, 29, 7215-7230, https://doi.org/10.1175/JCLI-D-15-0620.1.

Hu, Z.-Z., R. Wu, L. J. Kinter, and S. Yang, 2005: Connection of summer rainfall variations in South and East Asia: Role of El Niño-Southern Oscillation. Int. J. Climatol., 25, 1279-1289, https://doi.org/10.1002/joc.1159.

Huffman, G. J., and Coauthors, 2001: Global precipitation at one-degree daily resolution from multisatellite observations. J. Hydrometeor., 2, 36-50, https://doi.org/10.1175/ 1525-7541(2001)002<0036:GPAODD>2.0.CO;2.

Jia, X. L., and S. Yang, 2013: Impact of the quasi-biweekly oscillation over the western North Pacific on East Asian subtropical monsoon during early summer. J. Geophys. Res. Atmos., 118, 4421-4434, https://doi.org/10.1002/jgrd.50422.

Jiang, X., and M. Ting, 2017: A dipole pattern of summertime rainfall across the Indian subcontinent and the Tibetan Plateau. J. Climate, 30, 9607-9620, https://doi.org/10.1175/ JCLI-D-16-0914.1.

— T. Ti, and B. Wang, 2004: Structures and mechanisms of the northward propagating boreal summer intraseasonal oscillation. J. Climate, 17, 1022-1039, https://doi.org/10.1175/ 1520-0442(2004)017<1022:SAMOTN>2.0.CO;2.

_ , Y. Li, S. Yang, K. Yang, and J. Chen, 2016: Interannual variation of summer atmospheric heat source over the Tibetan Plateau and the role of convection around the western Maritime Continent. J. Climate, 29, 121-138, https://doi.org/ 10.1175/JCLI-D-15-0181.1. 
Kikuchi, K., and B. Wang, 2009: Global perspective of the quasibiweekly oscillation. J. Climate, 22, 1340-1359, https://doi.org/ 10.1175/2008JCLI2368.1.

- - - and Y. Kajikawa, 2012: Bimodal representation of the tropical intraseasonal oscillation. Climate Dyn., 38, 1989-2000, https://doi.org/10.1007/s00382-011-1159-1.

Krishnamurthy, V., and J. Shukla, 2007: Intraseasonal and seasonally persisting patterns of Indian monsoon rainfall J. Climate, 20, 3-20, https://doi.org/10.1175/JCLI3981.1.

$\longrightarrow$, and - 2008: Seasonal persistence and propagation of intraseasonal patterns over the Indian monsoon region. Climate Dyn., 30, 353-369, https://doi.org/10.1007/s00382-007-0300-7.

— , and R. S. Ajayamohan, 2010: Composite structure of monsoon low pressure systems and its relation to Indian rainfall. J. Climate, 23, 4285-4305, https://doi.org/10.1175/ 2010JCLI2953.1.

Liebmann, B., and C. A. Smith, 1996: Description of a complete (interpolated) outgoing longwave radiation dataset. Bull. Amer. Meteor. Soc., 77, 1275-1277.

Liu, F. M., and H. Lin, 1991: Relationships between the atmospheric low-frequency oscillation and the variation of the South Asian high (in Chinese). Plateau Meteor., 10, 61-69.

Murata, F., and Coauthors, 2017: Dominant synoptic disturbance in the extreme rainfall at Cherrapunji, northeast India, based on 104 years of rainfall data (1902-2005). J. Climate, 30, 8237-8251, https://doi.org/10.1175/JCLI-D-16-0435.1.

North, G. R., T. L. Bell, R. F. Cahalan, and F. J. Moeng, 1982: Sampling errors in the estimation of empirical orthogonal functions. Mon. Wea. Rev., 110, 699-706, https://doi.org/ 10.1175/1520-0493(1982)110<0699:SEITEO > 2.0.CO;2.

Qi, Y., R. Zhang, T. Li, and M. Wen, 2008: Interactions between the summer mean monsoon and the intraseasonal oscillation in the Indian monsoon region. Geophys. Res. Lett., 35, L17704, https://doi.org/10.1029/2008GL034517.

Suhas, E., J. M. Neena, and B. N. Goswami, 2013: An Indian monsoon intraseasonal oscillations (MISO) index for real time monitoring and forecast verification. Climate Dyn., 40, 26052616, https://doi.org/10.1007/s00382-012-1462-5.

Terao, T., 1998: Barotropic disturbances on intraseasonal time scales observed in the midlatitudes over the Eurasian continent during the northern summer. J. Meteor. Soc. Japan, 76, 419-436, https://doi.org/10.2151/jmsj1965.76.3_419.

Wang, M., and A. Duan, 2015: Quasi-biweekly oscillation over the Tibetan Plateau and its link with the Asian summer monsoon. J. Climate, 28, 4921-4940, https://doi.org/10.1175/ JCLI-D-14-00658.1.

Wang, Z., A. Duan, and G. Wu, 2014: Time-lagged impact of spring sensible heat over the Tibetan Plateau on the summer rainfall anomaly in East China: Case studies using the WRF model. Climate Dyn., 42, 2885-2898, https://doi.org/10.1007/ s00382-013-1800-2.

Wu, G., and Coauthors, 2007: The influence of mechanical and thermal forcing by the Tibetan Plateau on Asian climate. J. Hydrometeor., 8, 770-789, https://doi.org/10.1175/JHM609.1.

Yang, J., Q. Bao, B. Wang, D.-Y. Gong, H. He, and M.-N. Gao, 2014: Distinct quasi-biweekly variations of the subtropical East Asian monsoon during early and late summers. Climate Dyn., 42, 1469-1486, https://doi.org/10.1007/ s00382-013-1728-6.

Yao, T., and Coauthors, 2013: A review of climatic controls on $\delta^{18} \mathrm{O}$ in precipitation over the Tibetan Plateau: Observations and simulations. Rev. Geophys., 51, 525-548, https://doi.org/ 10.1002/rog.20023.

Yasunari, T., 1979: Cloudiness fluctuations associated with the Northern Hemisphere summer monsoon. J. Meteor. Soc. Japan, 57, 227-242, https://doi.org/10.2151/jmsj1965.57.3_227.

Yatagai, A., K. Kamiguchi, O. Arakawa, A. Hamada, N. Yasutomi, and A. Kitoh, 2012: APHRODITE: Constructing a long-term daily gridded rainfall dataset for Asia based on a dense network of rain gauges. Bull. Amer. Meteor. Soc., 93, 1401-1415, https://doi.org/10.1175/BAMS-D-11-00122.1.

Zhang, P. F., G. P. Li, X. H. Fu, Y. M. Liu, and L. F. Li, 2014: Clustering of Tibetan Plateau vortices by 10-30-day intraseasonal oscillation. Mon. Wea. Rev., 142, 290-300, https:// doi.org/10.1175/MWR-D-13-00137.1.

Zhou, L., H. Zou, S. Ma, F. Li, J. Zhu, P. Li, and Y. Zhang, 2015: The observed impacts of South Asian summer monsoon on the local atmosphere and the near-surface turbulent heat exchange over the Southeast Tibet. J. Geophys. Res., 120, 11509-11518, https://doi.org/10.1002/2014JD022928. 